KYOTO PROTOCOL TO THE UNITED NATIONS FRAMEWORK

CONVENTION ON CLIMATE CHANGE

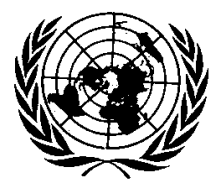

UNITED NATIONS

1998 


\section{KYOTO PROTOCOL TO THE UNITED NATIONS FRAMEWORK CONVENTION ON CLIMATE CHANGE}

\section{The Parties to this Protocol,}

Being Parties to the United Nations Framework Convention on Climate Change, hereinafter referred to as "the Convention",

In pursuit of the ultimate objective of the Convention as stated in its Article 2,

Recalling the provisions of the Convention,

Being guided by Article 3 of the Convention,

Pursuant to the Berlin Mandate adopted by decision 1/CP.1 of the Conference of the Parties to the Convention at its first session,

Have agreed as follows:

\section{Article 1}

For the purposes of this Protocol, the definitions contained in Article 1 of the Convention shall apply. In addition:

1. "Conference of the Parties" means the Conference of the Parties to the Convention.

2. "Convention" means the United Nations Framework Convention on Climate Change, adopted in New York on 9 May 1992.

3. "Intergovernmental Panel on Climate Change" means the Intergovernmental Panel on Climate Change established in 1988 jointly by the World Meteorological Organization and the United Nations Environment Programme.

4. "Montreal Protocol" means the Montreal Protocol on Substances that Deplete the Ozone Layer, adopted in Montreal on 16 September 1987 and as subsequently adjusted and amended.

5. "Parties present and voting" means Parties present and casting an affirmative or negative vote.

6. "Party" means, unless the context otherwise indicates, a Party to this Protocol.

7. "Party included in Annex I" means a Party included in Annex I to the Convention, as may be amended, or a Party which has made a notification under Article 4, paragraph 2 (g), of the Convention.

\section{Article 2}

1. Each Party included in Annex I, in achieving its quantified emission limitation and reduction commitments under Article 3, in order to promote sustainable development, shall: 
(a) Implement and/or further elaborate policies and measures in accordance with its national circumstances, such as:

(i) Enhancement of energy efficiency in relevant sectors of the national economy;

(ii) Protection and enhancement of sinks and reservoirs of greenhouse gases not controlled by the Montreal Protocol, taking into account its commitments under relevant international environmental agreements; promotion of sustainable forest management practices, afforestation and reforestation;

(iii) Promotion of sustainable forms of agriculture in light of climate change considerations;

(iv) Research on, and promotion, development and increased use of, new and renewable forms of energy, of carbon dioxide sequestration technologies and of advanced and innovative environmentally sound technologies;

(v) Progressive reduction or phasing out of market imperfections, fiscal incentives, tax and duty exemptions and subsidies in all greenhouse gas emitting sectors that run counter to the objective of the Convention and application of market instruments;

(vi) Encouragement of appropriate reforms in relevant sectors aimed at promoting policies and measures which limit or reduce emissions of greenhouse gases not controlled by the Montreal Protocol;

(vii) Measures to limit and/or reduce emissions of greenhouse gases not controlled by the Montreal Protocol in the transport sector;

(viii) Limitation and/or reduction of methane emissions through recovery and use in waste management, as well as in the production, transport and distribution of energy;

(b) Cooperate with other such Parties to enhance the individual and combined effectiveness of their policies and measures adopted under this Article, pursuant to Article 4, paragraph 2 (e) (i), of the Convention. To this end, these Parties shall take steps to share their experience and exchange information on such policies and measures, including developing ways of improving their comparability, transparency and effectiveness. The Conference of the Parties serving as the meeting of the Parties to this Protocol shall, at its first session or as soon as practicable thereafter, consider ways to facilitate such cooperation, taking into account all relevant information.

2. The Parties included in Annex I shall pursue limitation or reduction of emissions of greenhouse gases not controlled by the Montreal Protocol from aviation and marine bunker fuels, working through the International Civil Aviation Organization and the International Maritime Organization, respectively. 
3. The Parties included in Annex I shall strive to implement policies and measures under this Article in such a way as to minimize adverse effects, including the adverse effects of climate change, effects on international trade, and social, environmental and economic impacts on other Parties, especially developing country Parties and in particular those identified in Article 4, paragraphs 8 and 9, of the Convention, taking into account Article 3 of the Convention. The Conference of the Parties serving as the meeting of the Parties to this Protocol may take further action, as appropriate, to promote the implementation of the provisions of this paragraph.

4. The Conference of the Parties serving as the meeting of the Parties to this Protocol, if it decides that it would be beneficial to coordinate any of the policies and measures in paragraph 1 (a) above, taking into account different national circumstances and potential effects, shall consider ways and means to elaborate the coordination of such policies and measures.

\section{Article 3}

1. The Parties included in Annex I shall, individually or jointly, ensure that their aggregate anthropogenic carbon dioxide equivalent emissions of the greenhouse gases listed in Annex A do not exceed their assigned amounts, calculated pursuant to their quantified emission limitation and reduction commitments inscribed in Annex B and in accordance with the provisions of this Article, with a view to reducing their overall emissions of such gases by at least 5 per cent below 1990 levels in the commitment period 2008 to 2012.

2. Each Party included in Annex I shall, by 2005, have made demonstrable progress in achieving its commitments under this Protocol.

3. The net changes in greenhouse gas emissions by sources and removals by sinks resulting from direct human-induced land-use change and forestry activities, limited to afforestation, reforestation and deforestation since 1990, measured as verifiable changes in carbon stocks in each commitment period, shall be used to meet the commitments under this Article of each Party included in Annex I. The greenhouse gas emissions by sources and removals by sinks associated with those activities shall be reported in a transparent and verifiable manner and reviewed in accordance with Articles 7 and 8.

4. Prior to the first session of the Conference of the Parties serving as the meeting of the Parties to this Protocol, each Party included in Annex I shall provide, for consideration by the Subsidiary Body for Scientific and Technological Advice, data to establish its level of carbon stocks in 1990 and to enable an estimate to be made of its changes in carbon stocks in subsequent years. The Conference of the Parties serving as the meeting of the Parties to this Protocol shall, at its first session or as soon as practicable thereafter, decide upon modalities, rules and guidelines as to how, and which, additional human-induced activities related to changes in greenhouse gas emissions by sources and removals by sinks in the agricultural soils and the land-use change and forestry categories shall be added to, or subtracted from, the assigned amounts for Parties included in Annex I, taking into account uncertainties, transparency in reporting, verifiability, the methodological work of the Intergovernmental Panel on Climate Change, the advice provided by the Subsidiary Body for Scientific and Technological Advice in accordance with Article 5 and the decisions of the Conference of the Parties. Such a decision shall apply in the second and subsequent commitment periods. A Party may choose to apply such a decision on these additional human-induced activities for its first commitment period, provided that these activities have taken place since 1990. 
5. The Parties included in Annex I undergoing the process of transition to a market economy whose base year or period was established pursuant to decision 9/CP.2 of the Conference of the Parties at its second session shall use that base year or period for the implementation of their commitments under this Article. Any other Party included in Annex I undergoing the process of transition to a market economy which has not yet submitted its first national communication under Article 12 of the Convention may also notify the Conference of the Parties serving as the meeting of the Parties to this Protocol that it intends to use an historical base year or period other than 1990 for the implementation of its commitments under this Article. The Conference of the Parties serving as the meeting of the Parties to this Protocol shall decide on the acceptance of such notification.

6. Taking into account Article 4, paragraph 6, of the Convention, in the implementation of their commitments under this Protocol other than those under this Article, a certain degree of flexibility shall be allowed by the Conference of the Parties serving as the meeting of the Parties to this Protocol to the Parties included in Annex I undergoing the process of transition to a market economy.

7. In the first quantified emission limitation and reduction commitment period, from 2008 to 2012, the assigned amount for each Party included in Annex I shall be equal to the percentage inscribed for it in Annex B of its aggregate anthropogenic carbon dioxide equivalent emissions of the greenhouse gases listed in Annex A in 1990, or the base year or period determined in accordance with paragraph 5 above, multiplied by five. Those Parties included in Annex I for whom land-use change and forestry constituted a net source of greenhouse gas emissions in 1990 shall include in their 1990 emissions base year or period the aggregate anthropogenic carbon dioxide equivalent emissions by sources minus removals by sinks in 1990 from land-use change for the purposes of calculating their assigned amount.

8. Any Party included in Annex I may use 1995 as its base year for hydrofluorocarbons, perfluorocarbons and sulphur hexafluoride, for the purposes of the calculation referred to in paragraph 7 above.

9. Commitments for subsequent periods for Parties included in Annex I shall be established in amendments to Annex B to this Protocol, which shall be adopted in accordance with the provisions of Article 21, paragraph 7. The Conference of the Parties serving as the meeting of the Parties to this Protocol shall initiate the consideration of such commitments at least seven years before the end of the first commitment period referred to in paragraph 1 above.

10. Any emission reduction units, or any part of an assigned amount, which a Party acquires from another Party in accordance with the provisions of Article 6 or of Article 17 shall be added to the assigned amount for the acquiring Party.

11. Any emission reduction units, or any part of an assigned amount, which a Party transfers to another Party in accordance with the provisions of Article 6 or of Article 17 shall be subtracted from the assigned amount for the transferring Party.

12. Any certified emission reductions which a Party acquires from another Party in accordance with the provisions of Article 12 shall be added to the assigned amount for the acquiring Party. 
13. If the emissions of a Party included in Annex I in a commitment period are less than its assigned amount under this Article, this difference shall, on request of that Party, be added to the assigned amount for that Party for subsequent commitment periods.

14. Each Party included in Annex I shall strive to implement the commitments mentioned in paragraph 1 above in such a way as to minimize adverse social, environmental and economic impacts on developing country Parties, particularly those identified in Article 4, paragraphs 8 and 9, of the Convention. In line with relevant decisions of the Conference of the Parties on the implementation of those paragraphs, the Conference of the Parties serving as the meeting of the Parties to this Protocol shall, at its first session, consider what actions are necessary to minimize the adverse effects of climate change and/or the impacts of response measures on Parties referred to in those paragraphs. Among the issues to be considered shall be the establishment of funding, insurance and transfer of technology.

\section{Article 4}

1. Any Parties included in Annex I that have reached an agreement to fulfil their commitments under Article 3 jointly, shall be deemed to have met those commitments provided that their total combined aggregate anthropogenic carbon dioxide equivalent emissions of the greenhouse gases listed in Annex A do not exceed their assigned amounts calculated pursuant to their quantified emission limitation and reduction commitments inscribed in Annex B and in accordance with the provisions of Article 3. The respective emission level allocated to each of the Parties to the agreement shall be set out in that agreement.

2. The Parties to any such agreement shall notify the secretariat of the terms of the agreement on the date of deposit of their instruments of ratification, acceptance or approval of this Protocol, or accession thereto. The secretariat shall in turn inform the Parties and signatories to the Convention of the terms of the agreement.

3. Any such agreement shall remain in operation for the duration of the commitment period specified in Article 3, paragraph 7.

4. If Parties acting jointly do so in the framework of, and together with, a regional economic integration organization, any alteration in the composition of the organization after adoption of this Protocol shall not affect existing commitments under this Protocol. Any alteration in the composition of the organization shall only apply for the purposes of those commitments under Article 3 that are adopted subsequent to that alteration.

5. In the event of failure by the Parties to such an agreement to achieve their total combined level of emission reductions, each Party to that agreement shall be responsible for its own level of emissions set out in the agreement.

6. If Parties acting jointly do so in the framework of, and together with, a regional economic integration organization which is itself a Party to this Protocol, each member State of that regional economic integration organization individually, and together with the regional economic integration organization acting in accordance with Article 24, shall, in the event of failure to achieve the total combined level of emission reductions, be responsible for its level of emissions as notified in accordance with this Article. 


\section{Article 5}

1. Each Party included in Annex I shall have in place, no later than one year prior to the start of the first commitment period, a national system for the estimation of anthropogenic emissions by sources and removals by sinks of all greenhouse gases not controlled by the Montreal Protocol. Guidelines for such national systems, which shall incorporate the methodologies specified in paragraph 2 below, shall be decided upon by the Conference of the Parties serving as the meeting of the Parties to this Protocol at its first session.

2. Methodologies for estimating anthropogenic emissions by sources and removals by sinks of all greenhouse gases not controlled by the Montreal Protocol shall be those accepted by the Intergovernmental Panel on Climate Change and agreed upon by the Conference of the Parties at its third session. Where such methodologies are not used, appropriate adjustments shall be applied according to methodologies agreed upon by the Conference of the Parties serving as the meeting of the Parties to this Protocol at its first session. Based on the work of, inter alia, the Intergovernmental Panel on Climate Change and advice provided by the Subsidiary Body for Scientific and Technological Advice, the Conference of the Parties serving as the meeting of the Parties to this Protocol shall regularly review and, as appropriate, revise such methodologies and adjustments, taking fully into account any relevant decisions by the Conference of the Parties.

Any revision to methodologies or adjustments shall be used only for the purposes of ascertaining compliance with commitments under Article 3 in respect of any commitment period adopted subsequent to that revision.

3. The global warming potentials used to calculate the carbon dioxide equivalence of anthropogenic emissions by sources and removals by sinks of greenhouse gases listed in Annex A shall be those accepted by the Intergovernmental Panel on Climate Change and agreed upon by the Conference of the Parties at its third session. Based on the work of, inter alia, the Intergovernmental Panel on Climate Change and advice provided by the Subsidiary Body for Scientific and Technological Advice, the Conference of the Parties serving as the meeting of the Parties to this Protocol shall regularly review and, as appropriate, revise the global warming potential of each such greenhouse gas, taking fully into account any relevant decisions by the Conference of the Parties. Any revision to a global warming potential shall apply only to commitments under Article 3 in respect of any commitment period adopted subsequent to that revision.

\section{Article 6}

1. For the purpose of meeting its commitments under Article 3, any Party included in Annex I may transfer to, or acquire from, any other such Party emission reduction units resulting from projects aimed at reducing anthropogenic emissions by sources or enhancing anthropogenic removals by sinks of greenhouse gases in any sector of the economy, provided that:

(a) Any such project has the approval of the Parties involved;

(b) Any such project provides a reduction in emissions by sources, or an enhancement of removals by sinks, that is additional to any that would otherwise occur; 
(c) It does not acquire any emission reduction units if it is not in compliance with its obligations under Articles 5 and 7; and

(d) The acquisition of emission reduction units shall be supplemental to domestic actions for the purposes of meeting commitments under Article 3.

2. The Conference of the Parties serving as the meeting of the Parties to this Protocol may, at its first session or as soon as practicable thereafter, further elaborate guidelines for the implementation of this Article, including for verification and reporting.

3. A Party included in Annex I may authorize legal entities to participate, under its responsibility, in actions leading to the generation, transfer or acquisition under this Article of emission reduction units.

4. If a question of implementation by a Party included in Annex I of the requirements referred to in this Article is identified in accordance with the relevant provisions of Article 8, transfers and acquisitions of emission reduction units may continue to be made after the question has been identified, provided that any such units may not be used by a Party to meet its commitments under Article 3 until any issue of compliance is resolved.

\section{Article 7}

1. Each Party included in Annex I shall incorporate in its annual inventory of anthropogenic emissions by sources and removals by sinks of greenhouse gases not controlled by the Montreal Protocol, submitted in accordance with the relevant decisions of the Conference of the Parties, the necessary supplementary information for the purposes of ensuring compliance with Article 3, to be determined in accordance with paragraph 4 below.

2. Each Party included in Annex I shall incorporate in its national communication, submitted under Article 12 of the Convention, the supplementary information necessary to demonstrate compliance with its commitments under this Protocol, to be determined in accordance with paragraph 4 below.

3. Each Party included in Annex I shall submit the information required under paragraph 1 above annually, beginning with the first inventory due under the Convention for the first year of the commitment period after this Protocol has entered into force for that Party. Each such Party shall submit the information required under paragraph 2 above as part of the first national communication due under the Convention after this Protocol has entered into force for it and after the adoption of guidelines as provided for in paragraph 4 below. The frequency of subsequent submission of information required under this Article shall be determined by the Conference of the Parties serving as the meeting of the Parties to this Protocol, taking into account any timetable for the submission of national communications decided upon by the Conference of the Parties.

4. The Conference of the Parties serving as the meeting of the Parties to this Protocol shall adopt at its first session, and review periodically thereafter, guidelines for the preparation of the information required under this Article, taking into account guidelines for the preparation of 
national communications by Parties included in Annex I adopted by the Conference of the Parties. The Conference of the Parties serving as the meeting of the Parties to this Protocol shall also, prior to the first commitment period, decide upon modalities for the accounting of assigned amounts.

\section{Article 8}

1. The information submitted under Article 7 by each Party included in Annex I shall be reviewed by expert review teams pursuant to the relevant decisions of the Conference of the Parties and in accordance with guidelines adopted for this purpose by the Conference of the Parties serving as the meeting of the Parties to this Protocol under paragraph 4 below. The information submitted under Article 7, paragraph 1, by each Party included in Annex I shall be reviewed as part of the annual compilation and accounting of emissions inventories and assigned amounts. Additionally, the information submitted under Article 7, paragraph 2, by each Party included in Annex I shall be reviewed as part of the review of communications.

2. Expert review teams shall be coordinated by the secretariat and shall be composed of experts selected from those nominated by Parties to the Convention and, as appropriate, by intergovernmental organizations, in accordance with guidance provided for this purpose by the Conference of the Parties.

3. The review process shall provide a thorough and comprehensive technical assessment of all aspects of the implementation by a Party of this Protocol. The expert review teams shall prepare a report to the Conference of the Parties serving as the meeting of the Parties to this Protocol, assessing the implementation of the commitments of the Party and identifying any potential problems in, and factors influencing, the fulfilment of commitments. Such reports shall be circulated by the secretariat to all Parties to the Convention. The secretariat shall list those questions of implementation indicated in such reports for further consideration by the Conference of the Parties serving as the meeting of the Parties to this Protocol.

4. The Conference of the Parties serving as the meeting of the Parties to this Protocol shall adopt at its first session, and review periodically thereafter, guidelines for the review of implementation of this Protocol by expert review teams taking into account the relevant decisions of the Conference of the Parties.

5. The Conference of the Parties serving as the meeting of the Parties to this Protocol shall, with the assistance of the Subsidiary Body for Implementation and, as appropriate, the Subsidiary Body for Scientific and Technological Advice, consider:

(a) The information submitted by Parties under Article 7 and the reports of the expert reviews thereon conducted under this Article; and

(b) Those questions of implementation listed by the secretariat under paragraph 3 above, as well as any questions raised by Parties.

6. Pursuant to its consideration of the information referred to in paragraph 5 above, the Conference of the Parties serving as the meeting of the Parties to this Protocol shall take decisions on any matter required for the implementation of this Protocol. 


\section{Article 9}

1. The Conference of the Parties serving as the meeting of the Parties to this Protocol shall periodically review this Protocol in the light of the best available scientific information and assessments on climate change and its impacts, as well as relevant technical, social and economic information. Such reviews shall be coordinated with pertinent reviews under the Convention, in particular those required by Article 4, paragraph 2 (d), and Article 7, paragraph 2 (a), of the Convention. Based on these reviews, the Conference of the Parties serving as the meeting of the Parties to this Protocol shall take appropriate action.

2. The first review shall take place at the second session of the Conference of the Parties serving as the meeting of the Parties to this Protocol. Further reviews shall take place at regular intervals and in a timely manner.

\section{Article 10}

All Parties, taking into account their common but differentiated responsibilities and their specific national and regional development priorities, objectives and circumstances, without introducing any new commitments for Parties not included in Annex I, but reaffirming existing commitments under Article 4, paragraph 1, of the Convention, and continuing to advance the implementation of these commitments in order to achieve sustainable development, taking into account Article 4, paragraphs 3, 5 and 7, of the Convention, shall:

(a) Formulate, where relevant and to the extent possible, cost-effective national and, where appropriate, regional programmes to improve the quality of local emission factors, activity data and/or models which reflect the socio-economic conditions of each Party for the preparation and periodic updating of national inventories of anthropogenic emissions by sources and removals by sinks of all greenhouse gases not controlled by the Montreal Protocol, using comparable methodologies to be agreed upon by the Conference of the Parties, and consistent with the guidelines for the preparation of national communications adopted by the Conference of the Parties;

(b) Formulate, implement, publish and regularly update national and, where appropriate, regional programmes containing measures to mitigate climate change and measures to facilitate adequate adaptation to climate change:

(i) Such programmes would, inter alia, concern the energy, transport and industry sectors as well as agriculture, forestry and waste management. Furthermore, adaptation technologies and methods for improving spatial planning would improve adaptation to climate change; and

(ii) Parties included in Annex I shall submit information on action under this Protocol, including national programmes, in accordance with Article 7; and other Parties shall seek to include in their national communications, as appropriate, information on programmes which contain measures that the Party believes contribute to addressing climate change and its adverse impacts, including the abatement of increases in greenhouse gas emissions, and enhancement of and removals by sinks, capacity building and adaptation measures; 
(c) Cooperate in the promotion of effective modalities for the development, application and diffusion of, and take all practicable steps to promote, facilitate and finance, as appropriate, the transfer of, or access to, environmentally sound technologies, know-how, practices and processes pertinent to climate change, in particular to developing countries, including the formulation of policies and programmes for the effective transfer of environmentally sound technologies that are publicly owned or in the public domain and the creation of an enabling environment for the private sector, to promote and enhance the transfer of, and access to, environmentally sound technologies;

(d) Cooperate in scientific and technical research and promote the maintenance and the development of systematic observation systems and development of data archives to reduce uncertainties related to the climate system, the adverse impacts of climate change and the economic and social consequences of various response strategies, and promote the development and strengthening of endogenous capacities and capabilities to participate in international and intergovernmental efforts, programmes and networks on research and systematic observation, taking into account Article 5 of the Convention;

(e) Cooperate in and promote at the international level, and, where appropriate, using existing bodies, the development and implementation of education and training programmes, including the strengthening of national capacity building, in particular human and institutional capacities and the exchange or secondment of personnel to train experts in this field, in particular for developing countries, and facilitate at the national level public awareness of, and public access to information on, climate change. Suitable modalities should be developed to implement these activities through the relevant bodies of the Convention, taking into account Article 6 of the Convention;

(f) Include in their national communications information on programmes and activities undertaken pursuant to this Article in accordance with relevant decisions of the Conference of the Parties; and

(g) Give full consideration, in implementing the commitments under this Article, to Article 4, paragraph 8 , of the Convention.

\section{Article 11}

1. In the implementation of Article 10, Parties shall take into account the provisions of Article 4, paragraphs 4, 5, 7, 8 and 9, of the Convention.

2. In the context of the implementation of Article 4, paragraph 1, of the Convention, in accordance with the provisions of Article 4, paragraph 3, and Article 11 of the Convention, and through the entity or entities entrusted with the operation of the financial mechanism of the Convention, the developed country Parties and other developed Parties included in Annex II to the Convention shall:

(a) Provide new and additional financial resources to meet the agreed full costs incurred by developing country Parties in advancing the implementation of existing commitments under Article 4, paragraph 1 (a), of the Convention that are covered in Article 10, subparagraph (a); and 
(b) Also provide such financial resources, including for the transfer of technology, needed by the developing country Parties to meet the agreed full incremental costs of advancing the implementation of existing commitments under Article 4, paragraph 1, of the Convention that are covered by Article 10 and that are agreed between a developing country Party and the international entity or entities referred to in Article 11 of the Convention, in accordance with that Article.

The implementation of these existing commitments shall take into account the need for adequacy and predictability in the flow of funds and the importance of appropriate burden sharing among developed country Parties. The guidance to the entity or entities entrusted with the operation of the financial mechanism of the Convention in relevant decisions of the Conference of the Parties, including those agreed before the adoption of this Protocol, shall apply mutatis mutandis to the provisions of this paragraph.

3. The developed country Parties and other developed Parties in Annex II to the Convention may also provide, and developing country Parties avail themselves of, financial resources for the implementation of Article 10, through bilateral, regional and other multilateral channels.

\section{Article 12}

1. A clean development mechanism is hereby defined.

2. The purpose of the clean development mechanism shall be to assist Parties not included in Annex I in achieving sustainable development and in contributing to the ultimate objective of the Convention, and to assist Parties included in Annex I in achieving compliance with their quantified emission limitation and reduction commitments under Article 3.

3. Under the clean development mechanism:

(a) Parties not included in Annex I will benefit from project activities resulting in certified emission reductions; and

(b) Parties included in Annex I may use the certified emission reductions accruing from such project activities to contribute to compliance with part of their quantified emission limitation and reduction commitments under Article 3, as determined by the Conference of the Parties serving as the meeting of the Parties to this Protocol.

4. The clean development mechanism shall be subject to the authority and guidance of the Conference of the Parties serving as the meeting of the Parties to this Protocol and be supervised by an executive board of the clean development mechanism.

5. Emission reductions resulting from each project activity shall be certified by operational entities to be designated by the Conference of the Parties serving as the meeting of the Parties to this Protocol, on the basis of:

(a) Voluntary participation approved by each Party involved; 
(b) Real, measurable, and long-term benefits related to the mitigation of climate change; and

(c) Reductions in emissions that are additional to any that would occur in the absence of the certified project activity.

6. The clean development mechanism shall assist in arranging funding of certified project activities as necessary.

7. The Conference of the Parties serving as the meeting of the Parties to this Protocol shall, at its first session, elaborate modalities and procedures with the objective of ensuring transparency, efficiency and accountability through independent auditing and verification of project activities.

8. The Conference of the Parties serving as the meeting of the Parties to this Protocol shall ensure that a share of the proceeds from certified project activities is used to cover administrative expenses as well as to assist developing country Parties that are particularly vulnerable to the adverse effects of climate change to meet the costs of adaptation.

9. Participation under the clean development mechanism, including in activities mentioned in paragraph 3 (a) above and in the acquisition of certified emission reductions, may involve private and/or public entities, and is to be subject to whatever guidance may be provided by the executive board of the clean development mechanism.

10. Certified emission reductions obtained during the period from the year 2000 up to the beginning of the first commitment period can be used to assist in achieving compliance in the first commitment period.

\section{Article 13}

1. The Conference of the Parties, the supreme body of the Convention, shall serve as the meeting of the Parties to this Protocol.

2. Parties to the Convention that are not Parties to this Protocol may participate as observers in the proceedings of any session of the Conference of the Parties serving as the meeting of the Parties to this Protocol. When the Conference of the Parties serves as the meeting of the Parties to this Protocol, decisions under this Protocol shall be taken only by those that are Parties to this Protocol.

3. When the Conference of the Parties serves as the meeting of the Parties to this Protocol, any member of the Bureau of the Conference of the Parties representing a Party to the Convention but, at that time, not a Party to this Protocol, shall be replaced by an additional member to be elected by and from amongst the Parties to this Protocol.

4. The Conference of the Parties serving as the meeting of the Parties to this Protocol shall keep under regular review the implementation of this Protocol and shall make, within its mandate, the decisions necessary to promote its effective implementation. It shall perform the functions assigned to it by this Protocol and shall: 
(a) Assess, on the basis of all information made available to it in accordance with the provisions of this Protocol, the implementation of this Protocol by the Parties, the overall effects of the measures taken pursuant to this Protocol, in particular environmental, economic and social effects as well as their cumulative impacts and the extent to which progress towards the objective of the Convention is being achieved;

(b) Periodically examine the obligations of the Parties under this Protocol, giving due consideration to any reviews required by Article 4, paragraph 2 (d), and Article 7, paragraph 2, of the Convention, in the light of the objective of the Convention, the experience gained in its implementation and the evolution of scientific and technological knowledge, and in this respect consider and adopt regular reports on the implementation of this Protocol;

(c) Promote and facilitate the exchange of information on measures adopted by the Parties to address climate change and its effects, taking into account the differing circumstances, responsibilities and capabilities of the Parties and their respective commitments under this Protocol;

(d) Facilitate, at the request of two or more Parties, the coordination of measures adopted by them to address climate change and its effects, taking into account the differing circumstances, responsibilities and capabilities of the Parties and their respective commitments under this Protocol;

(e) Promote and guide, in accordance with the objective of the Convention and the provisions of this Protocol, and taking fully into account the relevant decisions by the Conference of the Parties, the development and periodic refinement of comparable methodologies for the effective implementation of this Protocol, to be agreed on by the Conference of the Parties serving as the meeting of the Parties to this Protocol;

(f) Make recommendations on any matters necessary for the implementation of this Protocol;

(g) Seek to mobilize additional financial resources in accordance with Article 11, paragraph 2;

(h) Establish such subsidiary bodies as are deemed necessary for the implementation of this Protocol;

(i) Seek and utilize, where appropriate, the services and cooperation of, and information provided by, competent international organizations and intergovernmental and non-governmental bodies; and

(j) Exercise such other functions as may be required for the implementation of this Protocol, and consider any assignment resulting from a decision by the Conference of the Parties.

5. The rules of procedure of the Conference of the Parties and financial procedures applied under the Convention shall be applied mutatis mutandis under this Protocol, except as may be otherwise decided by consensus by the Conference of the Parties serving as the meeting of the Parties to this Protocol. 
6. The first session of the Conference of the Parties serving as the meeting of the Parties to this Protocol shall be convened by the secretariat in conjunction with the first session of the Conference of the Parties that is scheduled after the date of the entry into force of this Protocol. Subsequent ordinary sessions of the Conference of the Parties serving as the meeting of the Parties to this Protocol shall be held every year and in conjunction with ordinary sessions of the Conference of the Parties, unless otherwise decided by the Conference of the Parties serving as the meeting of the Parties to this Protocol.

7. Extraordinary sessions of the Conference of the Parties serving as the meeting of the Parties to this Protocol shall be held at such other times as may be deemed necessary by the Conference of the Parties serving as the meeting of the Parties to this Protocol, or at the written request of any Party, provided that, within six months of the request being communicated to the Parties by the secretariat, it is supported by at least one third of the Parties.

8. The United Nations, its specialized agencies and the International Atomic Energy Agency, as well as any State member thereof or observers thereto not party to the Convention, may be represented at sessions of the Conference of the Parties serving as the meeting of the Parties to this Protocol as observers. Any body or agency, whether national or international, governmental or non-governmental, which is qualified in matters covered by this Protocol and which has informed the secretariat of its wish to be represented at a session of the Conference of the Parties serving as the meeting of the Parties to this Protocol as an observer, may be so admitted unless at least one third of the Parties present object. The admission and participation of observers shall be subject to the rules of procedure, as referred to in paragraph 5 above.

\section{Article 14}

1. The secretariat established by Article 8 of the Convention shall serve as the secretariat of this Protocol.

2. Article 8, paragraph 2, of the Convention on the functions of the secretariat, and Article 8, paragraph 3, of the Convention on arrangements made for the functioning of the secretariat, shall apply mutatis mutandis to this Protocol. The secretariat shall, in addition, exercise the functions assigned to it under this Protocol.

\section{Article 15}

1. The Subsidiary Body for Scientific and Technological Advice and the Subsidiary Body for Implementation established by Articles 9 and 10 of the Convention shall serve as, respectively, the Subsidiary Body for Scientific and Technological Advice and the Subsidiary Body for Implementation of this Protocol. The provisions relating to the functioning of these two bodies under the Convention shall apply mutatis mutandis to this Protocol. Sessions of the meetings of the Subsidiary Body for Scientific and Technological Advice and the Subsidiary Body for Implementation of this Protocol shall be held in conjunction with the meetings of, respectively, the Subsidiary Body for Scientific and Technological Advice and the Subsidiary Body for Implementation of the Convention. 
2. Parties to the Convention that are not Parties to this Protocol may participate as observers in the proceedings of any session of the subsidiary bodies. When the subsidiary bodies serve as the subsidiary bodies of this Protocol, decisions under this Protocol shall be taken only by those that are Parties to this Protocol.

3. When the subsidiary bodies established by Articles 9 and 10 of the Convention exercise their functions with regard to matters concerning this Protocol, any member of the Bureaux of those subsidiary bodies representing a Party to the Convention but, at that time, not a party to this Protocol, shall be replaced by an additional member to be elected by and from amongst the Parties to this Protocol.

\section{Article 16}

The Conference of the Parties serving as the meeting of the Parties to this Protocol shall, as soon as practicable, consider the application to this Protocol of, and modify as appropriate, the multilateral consultative process referred to in Article 13 of the Convention, in the light of any relevant decisions that may be taken by the Conference of the Parties. Any multilateral consultative process that may be applied to this Protocol shall operate without prejudice to the procedures and mechanisms established in accordance with Article 18.

\section{Article 17}

The Conference of the Parties shall define the relevant principles, modalities, rules and guidelines, in particular for verification, reporting and accountability for emissions trading. The Parties included in Annex B may participate in emissions trading for the purposes of fulfilling their commitments under Article 3. Any such trading shall be supplemental to domestic actions for the purpose of meeting quantified emission limitation and reduction commitments under that Article.

\section{Article 18}

The Conference of the Parties serving as the meeting of the Parties to this Protocol shall, at its first session, approve appropriate and effective procedures and mechanisms to determine and to address cases of non-compliance with the provisions of this Protocol, including through the development of an indicative list of consequences, taking into account the cause, type, degree and frequency of non-compliance. Any procedures and mechanisms under this Article entailing binding consequences shall be adopted by means of an amendment to this Protocol.

\section{Article 19}

The provisions of Article 14 of the Convention on settlement of disputes shall apply mutatis mutandis to this Protocol.

\section{Article 20}

1. Any Party may propose amendments to this Protocol.

2. Amendments to this Protocol shall be adopted at an ordinary session of the Conference of the Parties serving as the meeting of the Parties to this Protocol. The text of any proposed amendment to this Protocol shall be communicated to the Parties by the secretariat at least 
six months before the meeting at which it is proposed for adoption. The secretariat shall also communicate the text of any proposed amendments to the Parties and signatories to the Convention and, for information, to the Depositary.

3. The Parties shall make every effort to reach agreement on any proposed amendment to this Protocol by consensus. If all efforts at consensus have been exhausted, and no agreement reached, the amendment shall as a last resort be adopted by a three-fourths majority vote of the Parties present and voting at the meeting. The adopted amendment shall be communicated by the secretariat to the Depositary, who shall circulate it to all Parties for their acceptance.

4. Instruments of acceptance in respect of an amendment shall be deposited with the Depositary. An amendment adopted in accordance with paragraph 3 above shall enter into force for those Parties having accepted it on the ninetieth day after the date of receipt by the Depositary of an instrument of acceptance by at least three fourths of the Parties to this Protocol.

5. The amendment shall enter into force for any other Party on the ninetieth day after the date on which that Party deposits with the Depositary its instrument of acceptance of the said amendment.

\section{Article 21}

1. Annexes to this Protocol shall form an integral part thereof and, unless otherwise expressly provided, a reference to this Protocol constitutes at the same time a reference to any annexes thereto. Any annexes adopted after the entry into force of this Protocol shall be restricted to lists, forms and any other material of a descriptive nature that is of a scientific, technical, procedural or administrative character.

2. Any Party may make proposals for an annex to this Protocol and may propose amendments to annexes to this Protocol.

3. Annexes to this Protocol and amendments to annexes to this Protocol shall be adopted at an ordinary session of the Conference of the Parties serving as the meeting of the Parties to this Protocol. The text of any proposed annex or amendment to an annex shall be communicated to the Parties by the secretariat at least six months before the meeting at which it is proposed for adoption. The secretariat shall also communicate the text of any proposed annex or amendment to an annex to the Parties and signatories to the Convention and, for information, to the Depositary.

4. The Parties shall make every effort to reach agreement on any proposed annex or amendment to an annex by consensus. If all efforts at consensus have been exhausted, and no agreement reached, the annex or amendment to an annex shall as a last resort be adopted by a three-fourths majority vote of the Parties present and voting at the meeting. The adopted annex or amendment to an annex shall be communicated by the secretariat to the Depositary, who shall circulate it to all Parties for their acceptance.

5. An annex, or amendment to an annex other than Annex A or B, that has been adopted in accordance with paragraphs 3 and 4 above shall enter into force for all Parties to this Protocol six months after the date of the communication by the Depositary to such Parties of the adoption of the annex or adoption of the amendment to the annex, except for those Parties that have 
notified the Depositary, in writing, within that period of their non-acceptance of the annex or amendment to the annex. The annex or amendment to an annex shall enter into force for Parties which withdraw their notification of non-acceptance on the ninetieth day after the date on which withdrawal of such notification has been received by the Depositary.

6. If the adoption of an annex or an amendment to an annex involves an amendment to this Protocol, that annex or amendment to an annex shall not enter into force until such time as the amendment to this Protocol enters into force.

7. Amendments to Annexes A and B to this Protocol shall be adopted and enter into force in accordance with the procedure set out in Article 20, provided that any amendment to Annex B shall be adopted only with the written consent of the Party concerned.

\section{Article 22}

1. Each Party shall have one vote, except as provided for in paragraph 2 below.

2. Regional economic integration organizations, in matters within their competence, shall exercise their right to vote with a number of votes equal to the number of their member States that are Parties to this Protocol. Such an organization shall not exercise its right to vote if any of its member States exercises its right, and vice versa.

\section{Article 23}

The Secretary-General of the United Nations shall be the Depositary of this Protocol.

\section{Article 24}

1. This Protocol shall be open for signature and subject to ratification, acceptance or approval by States and regional economic integration organizations which are Parties to the Convention. It shall be open for signature at United Nations Headquarters in New York from 16 March 1998 to 15 March 1999. This Protocol shall be open for accession from the day after the date on which it is closed for signature. Instruments of ratification, acceptance, approval or accession shall be deposited with the Depositary.

2. Any regional economic integration organization which becomes a Party to this Protocol without any of its member States being a Party shall be bound by all the obligations under this Protocol. In the case of such organizations, one or more of whose member States is a Party to this Protocol, the organization and its member States shall decide on their respective responsibilities for the performance of their obligations under this Protocol. In such cases, the organization and the member States shall not be entitled to exercise rights under this Protocol concurrently.

3. In their instruments of ratification, acceptance, approval or accession, regional economic integration organizations shall declare the extent of their competence with respect to the matters governed by this Protocol. These organizations shall also inform the Depositary, who shall in turn inform the Parties, of any substantial modification in the extent of their competence. 


\section{Article 25}

1. This Protocol shall enter into force on the ninetieth day after the date on which not less than 55 Parties to the Convention, incorporating Parties included in Annex I which accounted in total for at least 55 per cent of the total carbon dioxide emissions for 1990 of the Parties included in Annex I, have deposited their instruments of ratification, acceptance, approval or accession.

2. For the purposes of this Article, "the total carbon dioxide emissions for 1990 of the Parties included in Annex I" means the amount communicated on or before the date of adoption of this Protocol by the Parties included in Annex I in their first national communications submitted in accordance with Article 12 of the Convention.

3. For each State or regional economic integration organization that ratifies, accepts or approves this Protocol or accedes thereto after the conditions set out in paragraph 1 above for entry into force have been fulfilled, this Protocol shall enter into force on the ninetieth day following the date of deposit of its instrument of ratification, acceptance, approval or accession.

4. For the purposes of this Article, any instrument deposited by a regional economic integration organization shall not be counted as additional to those deposited by States members of the organization.

\section{Article 26}

No reservations may be made to this Protocol.

\section{Article 27}

1. At any time after three years from the date on which this Protocol has entered into force for a Party, that Party may withdraw from this Protocol by giving written notification to the Depositary.

2. Any such withdrawal shall take effect upon expiry of one year from the date of receipt by the Depositary of the notification of withdrawal, or on such later date as may be specified in the notification of withdrawal.

3. Any Party that withdraws from the Convention shall be considered as also having withdrawn from this Protocol.

\section{Article 28}

The original of this Protocol, of which the Arabic, Chinese, English, French, Russian and Spanish texts are equally authentic, shall be deposited with the Secretary-General of the United Nations.

DONE at Kyoto this eleventh day of December one thousand nine hundred and ninety-seven.

IN WITNESS WHEREOF the undersigned, being duly authorized to that effect, have affixed their signatures to this Protocol on the dates indicated. 


\section{Annex A}

\section{Greenhouse gases}

Carbon dioxide (C02)

Methane $(\mathrm{CH} 4)$

Nitrous oxide (N20)

Hydrofluorocarbons (HFCs)

Perfluorocarbons (PFCs)

Sulphur hexafluoride (SF6)

\section{Sectors/source categories}

Energy

Fuel combustion

Energy industries

Manufacturing industries and construction

Transport

Other sectors

Other

Fugitive emissions from fuels

Solid fuels

Oil and natural gas

Other

Industrial processes

Mineral products

Chemical industry

Metal production

Other production

Production of halocarbons and sulphur hexafluoride

Consumption of halocarbons and sulphur hexafluoride

Other

Solvent and other product use

Agriculture

Enteric fermentation

Manure management

Rice cultivation

Agricultural soils

Prescribed burning of savannas

Field burning of agricultural residues

Other

Waste

Solid waste disposal on land

Wastewater handling

Waste incineration

Other 


\section{Annex B}

Party

Australia

Austria

Belgium

Bulgaria*

Canada

Croatia*

Czech Republic*

Denmark

Estonia*

European Community

Finland

France

Germany

Greece

Hungary*

Iceland

Ireland

Italy

Japan

Latvia*

Liechtenstein

Lithuania*

Luxembourg

Monaco

Netherlands

New Zealand

Norway

Poland*

Portugal

Romania*

Russian Federation*

Slovakia*

Slovenia*

Spain

Sweden

Switzerland

Ukraine*

United Kingdom of Great

Britain and Northern Ireland

United States of America
Quantified emission limitation or reduction commitment (percentage of base year or period)

108

92

92

92

94

95

92

92

92

92

92

92

92

92

94

110

92

92

94

92

92

92

92

92

92

100

101

94

92

92

100

92

92

92

92

92

100

92

93

* Countries that are undergoing the process of transition to a market economy. 